\title{
The growing pains of community child health
}

\author{
Michael Rogers
}

Nineteen years ago, community child health was still an ill defined component of local authority health services in the original tripartite NHS, isolated and without clear career or training structures. Three major NHS reorganisations and one Court report ${ }^{1}$ later, it is being embraced by the expanding specialty of paediatrics, which has broadened its horizons beyond the confines of clinical practice in hospital to include concerns for child health issues in the community, and the investigation and pursuit of preventive approaches to children's health needs.

Progress has been made and the pace of change is rapid. The overall goals are clear: to establish a consultant led specialty within paediatrics, which contributes appropriately to a range of 'combined' services, ${ }^{2}$ providing effective secondary health care for children in both community and hospital settings. The ongoing effects on paediatrics as a whole will be considerable, its centre of gravity will shift, ${ }^{3}$ and paediatric specialty practice ${ }^{4}$ will in future need to concern itself as much with its broad community base as with its 'high tech' cutting edge in hospitals. ${ }^{56}$

Residual misunderstanding of the nature and scope of community child health still hinders further developments, particularly as training is now an immediate issue. This paper therefore sets out the contemporary community child health stall, and raises some of the relevant organisational and staffing issues which continue to cause difficulty.

\section{The specialty of community child health} SCOPE

The specialty has two broad aspects which overlap and complement each other:

(1) Clinical practice: particularly developmental medicine, neurology, all aspects of disability (including special educational and social needs), child protection, adoption, and fostering.

(2) 'Population paediatrics': this includes Institute of Child Health, Royal Liverpool Children's NHS Trust, Alder Hey, Liverpool

Correspondence to: Dr Michael Rogers, Department of Community Child Health,

Royal Liverpool

Children's NHS Trust,

Myrtle Street,

Liverpool L7 7DG. tive, statutory and advisory responsibilities to education authorities, social service departments, and voluntary agencies. (Education Act 1981, Children Act 1989, child protection etc.)

\section{INTERFACES}

In this context an interface is defined as an area of overlap and mutual interest between two disciplines or specialties, where (a) confusion about roles and responsibilities is likely without cooperation based on mutual understanding and respect, (b) gaps and overlap in service provision need to be avoided, (c) there is probably scope for fruitful collaboration in training, and (d) the situation may change with time as health needs change.

Community child health has interfaces with:

\section{Hospital paediatrics}

The hospital view of community child health often continues to be incomplete: community paediatrics enters the new partnership with a tradition of inadequate research and training, with many areas of community work outside the experience of hospital paediatricians. Combined hospital/community appointments may have helped to bridge the gap, but have created their own problems (see below).

This interface is what the creation of seamless 'combined' health services for children is all about, ${ }^{27}$ and at the outset of the current NHS reorganisation it was recognised that this would be much easier to achieve where community and hospital paediatrics share management structures and budgets. It is not yet clear to what extent these basic structures have been achieved, but it is doubtful whether even a majority of districts have combined services in this sense, and the ongoing creation of independent trusts (of hospital and/or community services in various combinations) has confused the picture. ${ }^{8}$

\section{Public health medicine}

A joint British Paediatric Association (BPA)/ Faculty of Public Health Medicine (FPHM) Working Party has produced a report exploring this area in detail. ${ }^{9}$ It is clear that the dogmatic distinction between clinical practice and community medicine made in 1974 was arbitrary and unsustainable. There will be variations in the management of these interface areas according to local staffing levels, expertise, and traditions; however aspects of infectious disease control (particularly immunisation programmes), child protection, and coordinating responsibilities for the forthcoming confidential inquiry into infant deaths, ${ }^{10}$ will probably pass increasingly to community paediatricians.

General practice

The introduction of child health surveillance 
into the new 1990 general practitioner (GP) contract, and the very tight time schedule for implementation, required both parties in this 'arranged' relationship to get to know each other as never before. Increased mutual understanding and respect have resulted, and both disciplines are benefiting. The scope for further collaboration in other areas of child health is obviously considerable.

\section{Child psychiatry and clinical psychology services for children}

This potentially valuable interface is still relatively unexplored in terms of emotional and behavioural problems in childhood. A major constraint on closer collaboration has been shortage of manpower, particularly in child psychiatry. The obvious importance of the mental health of children is not reflected in the inadequacies of child mental health services in many districts, yet the scope for community based approaches to prevention, early indentification, and effective intervention is obvious.

\section{Community nursing}

The professional links between community child health and community nurses, particularly health visitors, go back to the latter part of the 19th century. There have been two recent fundamental changes. First, an increasingly clear distinction between primary and secondary health care leaves health visitors and community child health doctors separated in this sense, with health visitors belonging with primary health care services and general practice. Secondly, where hospital and community paediatrics have joined forces in management terms, this also leaves health visitors elsewhere, in community units or trusts. The new relationships will need careful nurturing. Developments in the school health service make it likely that school nurses will contribute to secondary (specialist) child health care.

\section{PRIORITIES}

Community child health needs to pursue four interrelated objectives:

(1) To make organisation and staffing changes which (a) ensure that the service is consultant led and (b) develop the distinctive nature of the specialty.

(2) To contribute to an appropriate balance between hospital and community work in combined child health services.

(3) To ensure that service provision is related to identified health needs. This will mean preserving and developing certain traditional roles and tasks, abandoning others, and identifying and developing new areas of work.

(4) To continue to build a sound academic base for community child health, in terms of (a) undergraduate teaching (b) postgraduate teaching (within paediatrics and in partnership with general practice), and (c) research.
PRIMARY AND SECONDARY CARE

In becoming an integral part of secondary (specialist care), community child health should leave two traditional areas of work, immunisation procedures and child health surveillance, to primary care centred in general practice. ${ }^{1}$

There are no major problems concerning immunisation procedures, and steady progress has been made in transferring responsibility to general practice.

Child health surveillance is less straightforward, and debate continues. ${ }^{11-13}$ In pushing for a switch to general practice the government is, on the face of it, putting into effect an important recommendation of the Court report, ${ }^{1}$ and in order to save money may also aim to dismantle a large part of the clinical medical officer (CMO) workforce. Such a switch will, however, take time, and it remains completely unclear how large a general practice contribution to child health surveillance as a whole is likely to be. The training implications have been spelt out ${ }^{13}$ but are still greatly underestimated, particularly if standards are to be maintained and raised, and more money will have to be found for payment to GPs. In the meantime, and for as long as it takes, it will be necessary for community child health staff to continue to make up any shortfall in whole population cover, around the aggregate contribution from general practice in each health district.

\section{Towards a consultant led service}

A consultant led service requires a sufficient number of consultants in clearly defined posts ${ }^{14}$ with appropriate training and adequate support staffing levels. These objectives will not be attained overnight. In future, once an appropriate academic base, training, and career structures have been established, community child health should have no more difficulty than other specialties in maintaining adequate staffing levels. In the shorter term, providing the specialty with sufficiently firm foundations will necessitate tackling staffing and training issues with imagination and vigour.

NUMBER OF POSTS

Expansion has been rapid, and the BPA's unpublished manpower census in 1990 showed an increase in consultant posts from 68 in November 1988 to 139 in February 1990: numbers have certainly increased further since then. Thirty six districts then had two or more consultant paediatricians (community child health) (CPCCHs), but 89 districts still had no consultant community paediatricians; in these the service was presumably headed either by a consultant in public health medicine or a senior clinical medical officer (SCMO). Appointments had not been made in $20 \%$ of $\mathrm{CPCCH}$ posts advertised. For the future, staffing levels of one CCPCH per 100000 total population (equivalent to one per 1300 live births) are envisaged. ${ }^{15}$ On this basis, small districts would need one to two, most would justify two to four, and large districts five or more CCPCHs. 
COMBINED POSTS

A consultant post which combines hospital and community work is one of the models outlined by the BPA, ${ }^{14}$ and an unpublished survey by the BPA in 1991 indicated that $46 \%$ of CCPCHs currently in post do two or more hospital sessions per week. Such posts have two obvious short term advantages: they enable the service as it exists in this transitional period to be consultant led (if only on a part time basis), and on the face of it they will help to break down arbitrary distinctions between community and hospital services.

There are also disadvantages. First, most consultants in established combined posts have a background consisting almost entirely of hospital experience, suitable senior training posts in the community being a recent development. Areas of work with which they are unfamiliar will have been presented to such consultants, who will either have had to learn on the job (which is less than satisfactory), or they will have delegated these responsibilities to other staff, usually experienced SCMOs. As a result there are obvious leadership and training issues in these areas of work: for example, supervision of such training posts as exist is often inadequate. Secondly, it tends to be community sessions that get squeezed in the inevitable pressure of work in combined appointments. Thirdly, maintaining an acute 'on call' commitment, sufficient to maintain diagnostic and therapeutic sharpness, might also make it difficult to maintain a large community involvement. Finally, providing adequate training in both community and hospital paediatrics would prolong higher specialist training considerably. The longer term place of such combined posts therefore has to be questioned, and they should certainly not be regarded as a universal model. Even the smallest health district will need the equivalent of at least one full time CCPCH.

\section{FIRST GENERATION CONSULTANT COMMUNITY PAEDIATRICIANS}

Community paediatricians currently in post are a motley crew. Some come from a community background with relatively insufficient training in, and contact with, acute paediatrics. Others have a background of hospital training, with inadequate community experience. Fortunately the number of trainees with balanced experience is now slowly increasing.

A proper first generation 'skill mix' in the consultant workforce, both nationally and when extra CCPCH posts are created in larger districts, is crucial. A balance between hospital and community experience is essential to ensure high standards in all aspects of community child health work and training.

There are still SCMOs of consultant calibre who have not yet achieved consultant status, usually because they have not achieved the MRCP. They therefore fall at the hurdle of traditional Royal College appraisal at selection interviews, even for full time community posts, where their extensive experience and administrative aptitudes are completely appropriate and despite having been given retrospective accreditation by the Joint Committee on Higher Medical Training. They are not prototype CCPCHs of tomorrow, but their expertise makes them indispensable as first generation CCPCHs of today.

Standards in community child health must obviously be safeguarded for the future by appropriate entrance qualifications to general medical and higher specialist training. ${ }^{14}$ In the short term, say for a time limited period of three years, a means must be found to ensure that some SCMOs are incorporated into the consultant workforce by the kind of appraisal and selective upgrading recommended by the Duncan report ${ }^{16}$ and endorsed by the BPA. ${ }^{14}$ To date, no progress has been made on this important issue.

\section{A STAFF GRADE IN COMMUNITY CHILD HEALTH}

A CCPCH responsible for a geographical patch of 100000 total population, and probably also with a wider 'special interest' within a health district, will need at least two senior doctors working with him/her on the patch, in order to ensure a full range of service provision at senior level, including training, research, and adequate cover of annual, study, and sick leave.

Some of these senior doctors might be senior registrars, although creating sufficient training posts for a major service contribution at this level will be difficult. There remains a considerable gap which must be filled by a senior community staff grade, with appropriate career and training structures. In this respect, community child health is essentially different from hospital practice, and the hospital staffing model will not work in the community setting without this modification. The interim report of a Joint Working Party on Medical Services for Children has made a timely and very welcome acknowledgement of this requirement, without which the community senior staffing sums will not add up. ${ }^{17}$

The working party also identified the need for an ongoing basic level career grade in community child health, ${ }^{17}$ although their report confuses issues of primary and secondary care. Such doctors will be required, probably indefinitely, to complement the contribution of general practice to child health surveillance, and they will provide continuity around the service contribution of staff at senior house officer and registrar level, whose contracts will often be part time, and always short term by community standards. The staffing levels required have yet to be determined, depending on the extensive changes occurring in community child health. Appropriate and ongoing training for these staff must be given priority.

\section{THE FUTURE OF SCMOS AND CMOS}

The contribution and skills of SCMOs and CMOs need to be affirmed: the continuity they provide is critical for a successful shift to new patterns of more specialised practice over the next few years. Thereafter, those SCMOs who do not achieve consultant status, and do not retire, will certainly form the basis of the new 
senior staff grade. Likewise CMOs looking to make a longer term commitment and keen for appropriate training can also use the career structures of the two staff grades.

\section{THE COMMUNITY AS A PLACE TO WORK AND \\ TRAIN}

Unlike a hospital, which is a compact, closely knit, and straightforward environment in which to work, the community is diffuse and complex, and much of its work is interdisciplinary, with working environments, such as schools and social service nurseries, not under direct medical or health control. Considerable experience of a particular locality is needed before resources can be used effectively, and building up and maintaining personal professional contacts over time is crucial.

Continuity vested in the individual who fills a post rather than in the post itself is therefore essential, and training posts at senior registrar level need to be for a minimum of two years in one locality, both to ensure an integrated service contribution, and also to acquire in-depth experience as a model for subsequent work at consultant level.
1 Committee on Child Health Services. Fit for the future. London: HMSO, 1976. (Court report.)

2 British Paediatric Association. Towards a combined child health service. London: BPA, 1991.

3 Davis JA. Geriatric paediatrics. Arch Dis Child 1989;64: $1752-4$.

4 Eyre J, Boyd R, eds. Paediatric specialty practice for the 1990 s. London: Royal College of Physicians of London, 1991 .

5 Anonymous. Paediatrics or child health in the 1990s? [Editorial.] Lancet 1991;338:482.

6 Rogers MGH. Paediatrics or child health in the 1990s. Lancet 1991;338:889.

7 Appleyard WJ. Children's services in the new NHS-a struggle for survival? Arch Dis Child 1990;65:635-7.

8 British Paediatric Association. Management models in established combined or integrated child health services. London: BPA, 1992.

9 British Paediatric Association and Faculty of Public Health Medicine. Working together for tomorrow's children. Joint Working Party Discussion Document. London: BPA, 1990.

10 Health Care Parliamentary Monitor. Confidential enquiry into stillbirths and deaths in infancy. London: HMSO, January stillbirths and deaths in infancy. London: HMSO, January

11 Van Zwanenberg TD. Effect of the new GP contract on child health clinics. Arch Dis Child 1991;66:157-9.

12 Bellis K. Child health clinics. Arch Dis Child 1991;66:159-61. Hall DMB, ed. Health for all children. 2nd Ed. Oxford: Oxford University Press, 1991

14 British Paediatric Association. Consultant paediatrician (community child health): model job descriptions. London: BPA, 1991.

15 British Paediatric Association. Paediatric medical staffing for the '90s. London: BPA, 1991.

16 British Medical Association. Interim report of the child health forums. BMf 1986;292:1409.

17 Joint Working Party on Medical Services for Children. Interim report. London: Department of Health and British Interim report. London: Dep
Medical Association. 1992. 